\title{
Erratum: Extrapyramidal side effects in first-episode schizophrenia treated with flupenthixol decanoate
}

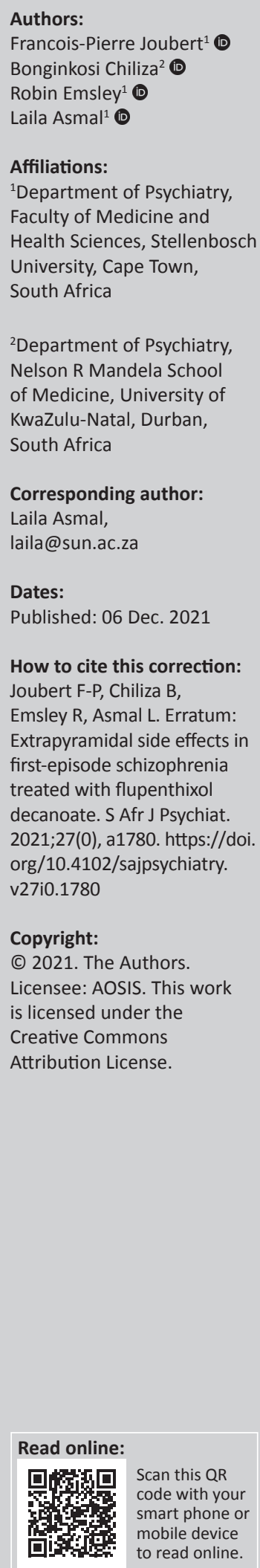

In the version of the article initially published, Joubert F-P, Chiliza B, Emsley R, Asmal L. Extrapyramidal side effects in first-episode schizophrenia treated with flupenthixol decanoate. S Afr J Psychiatr. 2021;27(0), a1568. https://doi.org/10.4102/sajpsychiatry.v27i0.1568, a sentence in the 'Conclusion' section of the abstract was given incorrectly. The correct sentence should be 'Ethnicity is a socio-cultural construct and the differential risk of EPSEs according to ethnicity should be interpreted accordingly' instead of 'Ethnicity is a socio-cultural construct, and hence the differential risk of EPSEs should be interpreted according to ethnicity'.

This correction does not alter the study's findings of significance or overall interpretation of the study's results. The publisher apologises for any inconvenience caused. 